\title{
Bibliometric Analysis of Research on the Comorbidity of Cancer and Pain
}

This article was published in the following Dove Press journal:

Journal of Pain Research

\author{
Cheng-Cheng $\mathrm{Wu}^{\mathrm{l}, *}$ \\ Yi-Zu Wang ${ }^{1, *}$ \\ $\mathrm{Hao}-\mathrm{Yu} \mathrm{Hu}{ }^{\prime}$ \\ Xue-Qiang Wang ${ }^{1,2}$
}

'Department of Sport Rehabilitation, Shanghai University of Sport, Shanghai, 200438, People's Republic of China; ${ }^{2}$ Department of Rehabilitation Medicine, Shanghai Shangti Orthopaedic Hospital, Shanghai, 200438, People's Republic of China

*These authors contributed equally to this work
Correspondence: Xue-Qiang Wang

Department of Sport Rehabilitation,

Shanghai University of Sport, 399 Changhai

Road, Shanghai 200438, People's Republic of

China

Tel +862I-65507362

Email qiang897@।63.com

Hao-Yu Hu

Department of Sport Rehabilitation,

Shanghai University of Sport, 399 Changhai

Road, Shanghai 200438, People's Republic of

China

Tel +86-18262630227

Email 472943082@qq.com
Background: Pain is the most common symptom in patients with neoplasm. It is a distressing experience that seriously destructs the quality-of-life of patients, with a high prevalence in clinical observations. However, only a few studies have applied bibliometric methods to analyze systematic works on the comorbidity of cancer and pain.

Purpose: The aim of this work was to conduct a systematic analysis of the scientific studies worldwide on the comorbidity of cancer and pain in 2010-2019.

Methods: The Web of Science databases were searched for publications related to the comorbidity of cancer and pain from 2010 to 2019.

Results: A total of 3,423 papers met the inclusion criteria in this research. The increase in the quantity of papers presented a significant growth from 2010 to $2019(P<0.001)$ by linear regression analysis. The research subject categories of the 3,423 papers mainly concentrated on oncology $(28.57 \%)$, clinical neurology $(25.62 \%)$, and healthcare science services $(15.89 \%)$. The US had the highest number of published papers, followed by the People's Republic of China, and England. According to scientific statistics, breast cancer $(20.36 \%)$ was by far the most predominant topic in the papers related to the comorbidity of cancer and pain.

Conclusion: This bibliometric research provided a framework for visual and quantitative research to management scholars in favor of exploring a potential field related to hot issue and research frontiers.

Keywords: global trend, pain, CiteSpace, cancer

\section{Introduction}

Cancer is a common disease, with more than 14 million cases worldwide annually (as reported by Cancer Research UK). It affects physical and emotional functions, making everyday activities and social interactions challenging. ${ }^{1,2}$ In 2018 , there were 18.1 million new cases of cancer and 9.6 million cancer deaths. ${ }^{3,4}$ The most common symptoms that routinely damage the quality-of-life of cancer patients include pain, anxiety, depression, and fatigue. ${ }^{1}$ As the study by Mariotto et $\mathrm{al}^{5}$ predicted, in the US, if incidence, survival, and cost remain the same, there would be 13.8 and 18.1 million cancer patients in 2010 and 2020, respectively, and the associated cancer treatment costs would be 124.57 and 157.77 billion 2010 US dollars.

Pain is a common distressing symptom associated with cancer, and it may be due to tissue destruction and sensory and emotional discomfort. ${ }^{1,6,7}$ According to the 2016 National Health Interview Survey data, approximately $20.4 \%$ (50.0 million) of the population in the US have chronic pain, and $8.0 \%$ of the 
population (19.6 million) have severe chronic pain. ${ }^{8}$ Despite advances in cancer therapies, nearly one out of two cancer patients remain undertreated for pain. ${ }^{9} \mathrm{Up}$ to $3 \%$ of the gross domestic product of European countries has been spent on pain treatment, which exceeds the expenditure on cancer and heart disease. ${ }^{10}$ Evidence suggests that adequate pain treatment results in clinically relevant improvements in health-related quality-oflife. $^{11}$

Cancer pain destroys the quality-of-life of patients and is linked with multiple psychosocial disorders. Previous studies found that moderate-to-severe pain was reported by $38.0 \%$ of patients and $51.9 \%$ in patients with advanced stage cancer. ${ }^{12}$ Compared with the tradition view, wherein cancer pain is associated with the physical effects of the growing neoplasm, count in the tissue destruction, and the immediate compression of serve fibers exist in the situation. ${ }^{13}$ Brown and Ramirez $^{14}$ showed that common signaling pathways, mediators, and immune cell types are involved in the generation of pain as a result of cancer and its treatment and distinct alterations in central and peripheral neuronal functions occur in multiple forms of cancer pain.

Bibliometrics is a statistical analysis and quantitative tool to study publications. Although research on cancer and pain is extensively available worldwide, to our knowledge studies using bibliometric methods to analyze the overall aspects of our study topic are limited. Bibliometric refers to methods that use the quantitative analysis of published research and statistics to confirm the trends of scientific research. ${ }^{15}$ In the past 10 years, bibliometric analyses have been conducted on other cancer research hotspots, such as the application of medicine, ${ }^{16}$ cancer rehabilitation, ${ }^{17,18}$ immunotherapy, ${ }^{19}$ risk of infection, ${ }^{20}$ medical literature, ${ }^{21}$ and public policy. $^{22}$

As we all know, with relatively few quantitative analyses of the comorbidity of cancer and pain, the purpose of this study is to methodically offer overall scientific analysis of published research within the past 10 years. CiesSpace $(5,5, \mathrm{R} 2)$, which was created by Professor Chaomei Chen in 2004, is designed to facilitate the detection of emerging trends and abrupt changes in scientific literature. To conduct a bibliometric research, we researched the Web of Science databases for publications related to the comorbidity of cancer and pain from 2010 to 2019 and used CiteSpace $(5,5, \mathrm{R} 2)$ to map the co-occurrence network map of countries, institutions, authors, keywords, and subject categories, as well as the co-citation networks of references, journals, authors, and citation burst analysis of keywords. ${ }^{23}$

\section{Materials and Methods Source of Data}

We used the Web of Science database as the basic retrieval tool. We also chose the Science Citation Index Expanded (SCI-Expanded) database of Web of Science (WoS) as the source of available databases. Published papers from 2010 to 2019 were retrieved. We set the record content terms as the title $=($ pain* or headache* or "head ache*" or head-ache* or migraine* or cephalalgi* or "stomach ache*" or "tummy ache*" or "abdominal ache*" or "belly ache*" or earache* or earache* or toothache* or tooth-ache* or odontalgi* or dysmenorrh* or neuralgi* or cervicodyn* or analg* or nocicept* or hyperalg* or hypoalg* or fibromyalg* or radiculalg* or colic or sciatic* or arthralg* or causalg* or eudyn* or maldyn* or brachialg* or ophthalmodyn* or cephalalg* or otalg*) and title=(cancer or tumor or tumour or neoplasia or neoplasms or tumors or tumours or cancers).

\section{Inclusion Criteria}

Articles and reviews related to the comorbidity of cancer and pain in different academic journals were included. We excluded letters, meeting abstracts, published editorial materials, book reviews, conference presentations, news items, and corrections. Language was unrestricted, and no restrictions on the species were specified.

\section{Data Extraction}

Cheng-Cheng $\mathrm{Wu}$ researched and extracted the publications related to the comorbidity of cancer and pain from the Web of Science databases from 2010 to 2019. EndNote X7 and Microsoft Excel 2016 were used for the statistical analysis of downloaded published research data. Information including the number of published papers was extracted and recorded as bibliometric indicators. We classified involved research in several ways: 1) types of cancer, 2) Web of Science subject category, and 3) single- or multiple-authored article (authors $\geq 2$ ). The author selected and evaluated the top 10 types of cancer (eg, breast cancer) according to involved studies. Given that certain publications focused on more than one type of cancer, the total of papers can reach more 
than 3,423 . For instance, the studies of Agarwal et $\mathrm{al}^{24}$ and Altundag et $\mathrm{al}^{25}$ focused on breast cancer and bone cancer.

\section{Statistical Methods}

We used CiteSpace (5, 5, R2) and Microsoft Excel 2016 for statistical analysis and obtained 1) the distribution of years/ journals/authors/institutions/countries, 2) cooperation among authors/countries/institutions, 3) quantity of citations and value of the $\mathrm{H}$-index, and 4) co-citation reference and keywords with the strongest citation bursts. To evaluate whether the percentage statistically decreased or increased from 2010 to 2019, we used IBM SPSS Statistics 18.0 software for linear regression analysis with the percentage of each category (as the dependent variable) and the year (as the independent variable), such as the percentage of publication count per year of types of cancer. $P<0.05$ was considered to indicate statistical significance.

\section{Results}

\section{Paper Analysis}

In total, 3,423 papers met the inclusion criteria. Figure 1A shows that the general trend of publications increased from 259 in 2010 to 452 in 2019. According to the feedback of linear regression results, the percentages had a remarkable growth from 2010 to $2019(\mathrm{t}=10.91, \mathrm{P}<0.001)$. The total number of publications on the comorbidity of cancer and pain reached up to 47,566-times (4,756.6-times annually, $\mathrm{H}$-index value $=83$ ). The percentages also revealed a remarkable growth from 2010 to $2019 \quad(\mathrm{t}=46.83$, $P<0.001$ ), as presented in Figure 1B. In detail, papers related to the comorbidity of cancer and pain were cited the most in 2011, which was up to 8,649-times, followed by 2010 . The highest H-index value (50) and largest number of citations per paper (33.4) were presented in 2011. The highest number of papers was published in 2019

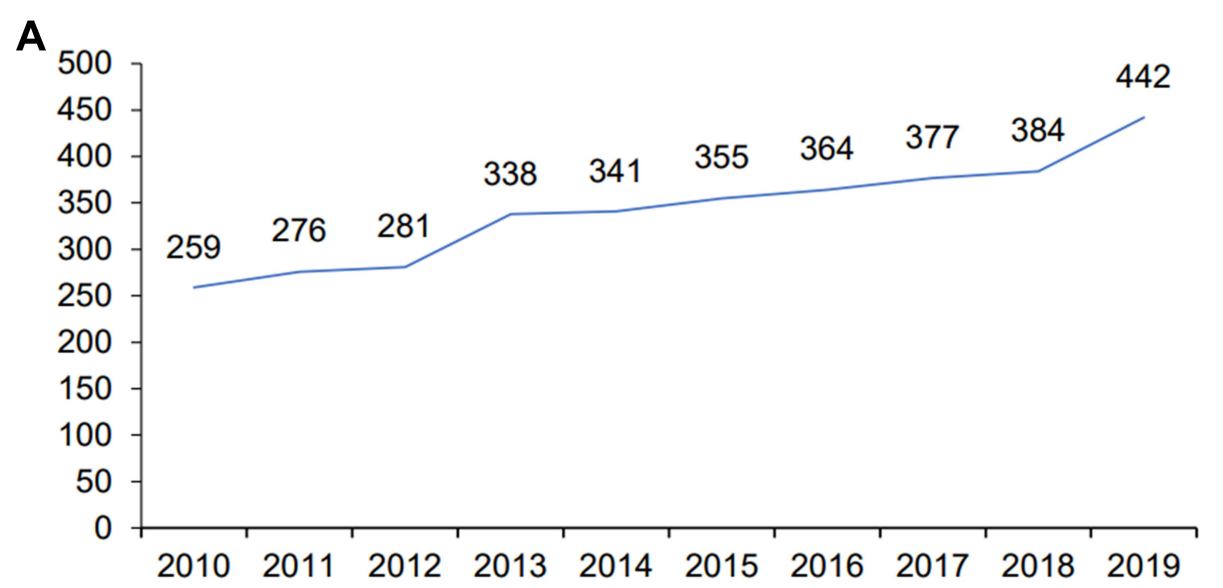

B

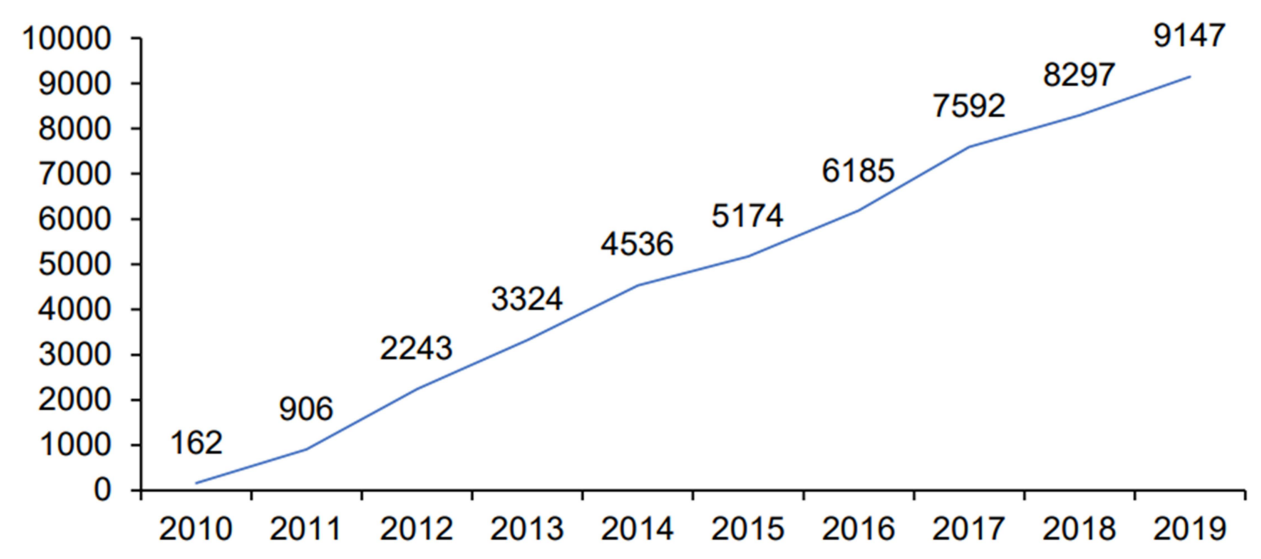

Figure I Number of publications and citations. (A) The number of annual publications on cancer and pain research from 20I0-2019; (B) the number of annual citations on cancer and pain research from 2010-2019. 


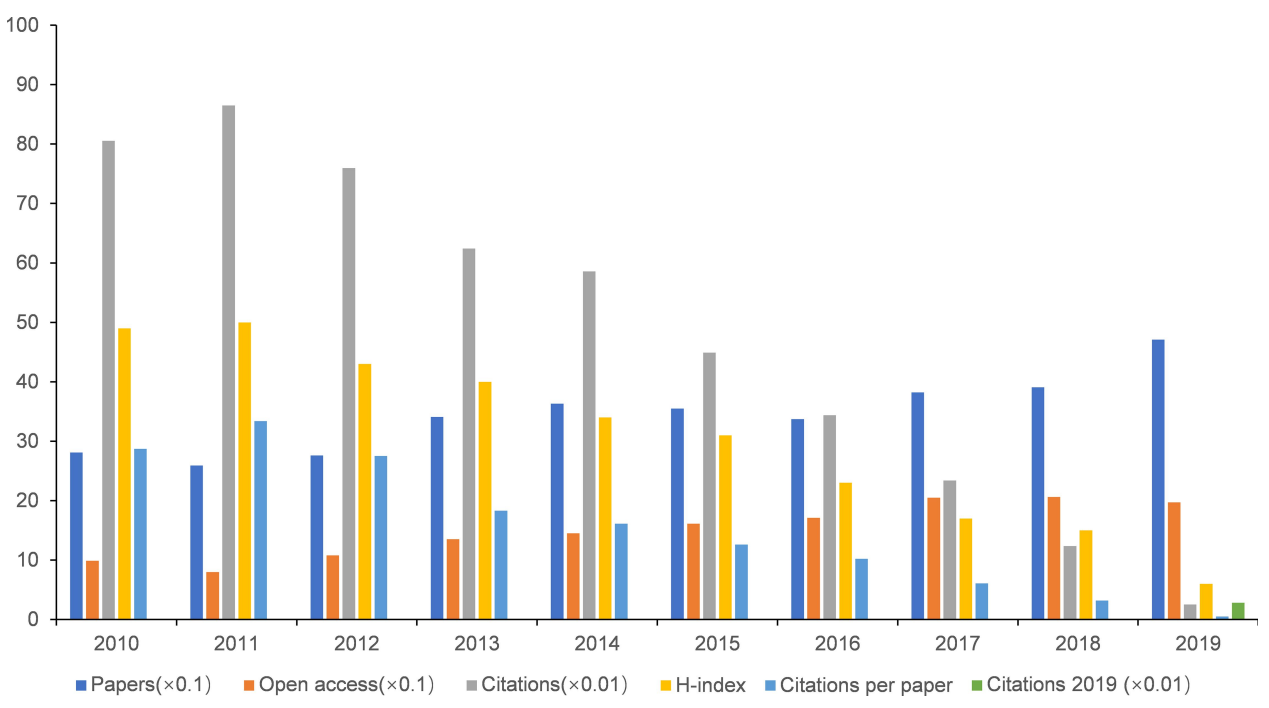

Figure 2 Number of papers, citations, citations per paper, open access paper, $\mathrm{H}$-index, and citations in 2019 for each year time period.

(471), and the highest number of open access papers was observed in 2018 (206), as shown in Figure 2.

\section{Analysis of Journals}

The publications searched was published in 841 academic journals, as shown in Supplementary Table 1. We selected and recorded the top 20 journals according to the quantity of papers, as shown in Table 1. The academic journal Supportive Care in Cancer with impact factor (IF) 2018 of 2.754 had the highest number of papers on the comorbidity of cancer and pain (139 publications, 4.03\%), followed by the Journal of Pain and Symptom Management (IF 2018, 3.378; 134 publications; 3.89\%), Pain (IF 2018, 6.029; 93 publications; 2.70\%), and Pain Medicine (IF $2018,2.764 ; 82$ publications; $2.38 \%$ ). In detail, the academic journal Pain had the highest $\mathrm{H}$-index value, which reached up to 33. Clinical Oncology had the largest quantity of citations per paper (57.48) and highest $2018 \mathrm{IF}$, of 28.349 .

As shown in Figure 3, CiteSpace $(5,5, \mathrm{R} 2)$ was used to gain a dual-map overlay of the journals. Interpreting the construction of a dual-map base, the left of the dual-map is the citing journals and the right of the dual-map is the cited journals. The labels of the dual map were considered as the discipline of the journals, and the lines were recognized as the connections of citation, that is, always beginning from the citing journals to the cited journals. As a result, the majority of publications were published in neurology, sports, and ophthalmology journals, which mostly cited journals from health, nursing, and medicine.

\section{Subject Categories of WOS Analysis}

The researched areas were distributed to 72 subject categories of WOS. We listed the top 20 subject categories according to the quantity of papers, as shown in Figure 4. In detail, Oncology had the largest quantity of papers (978), number of citations $(12,839)$, number of open access papers (410), and value of H-index (53). Neurosciences subject category had the largest number of citations per paper (19.37). According to the feedback of linear regression analyses, the percentages had a remarkable increase in the last 10 years in the top 20 categories (Oncology, Health Care Sciences Services, Pharmacology Pharmacy, Neurosciences, Rehabilitation, Medicine Research Experimental, Radiology Nuclear Medicine Medical Imaging, Integrative Complementary Medicine) $(P<0.05)$.

\section{Analysis of Types of Cancer}

According to the quantity of publications, we listed the top 10 types of cancer (Figure 5), the papers with breast cancer published quantity was the most in the top types researching on the comorbidity of cancer and pain (697, publications), which accounted for $20.36 \%$ of the total quantity of papers, followed by bone cancer (642 


\begin{tabular}{|c|c|c|c|c|c|c|c|c|c|c|c|c|c|c|c|c|c|c|c|c|}
\hline 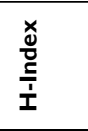 & $\stackrel{i}{\circ}$ & iे & ल & $\pi$ & i & $\sigma$ & $\underline{m}$ & $\hat{\lambda}$ & i & $=$ & $=$ & $\underline{m}$ & $\stackrel{\infty}{ }$ & $\stackrel{\sim}{2}$ & $\underline{m}$ & $\underline{a}$ & $\sigma$ & \pm & + & $\hat{\lambda}$ \\
\hline 总 & $\begin{array}{l}\ddot{\hat{O}} \\
\ddot{\tilde{\sigma}} \bar{\alpha}\end{array}$ & $\begin{array}{l}\ddot{\bar{\alpha}} \\
\ddot{\bar{\alpha}} \bar{o}\end{array}$ & $\begin{array}{l}\dot{\bar{\sigma}} \\
\ddot{\bar{\alpha}} \bar{\alpha}\end{array}$ & $\tilde{\sigma}$ & $\begin{array}{l}\tilde{\sigma} \\
\ddot{\sigma}\end{array}$ & య & $\ddot{\theta}$ & $\hat{\tilde{O}}$ & $\begin{array}{l}\bar{o} \\
\overline{\bar{\sigma}}\end{array}$ & $\tilde{\sigma}$ & $\stackrel{\tilde{O}}{0}$ & $\begin{array}{l}\dot{\tilde{\sigma}} \\
\dot{\tilde{\sigma}} \tilde{\sigma}\end{array}$ & $\bar{\alpha}$ & $\bar{\alpha}$ & $\begin{array}{l}\tilde{\sigma} \\
\dot{\tilde{\sigma}}\end{array}$ & $\begin{array}{l}\ddot{\bar{\alpha}} \\
\ddot{\bar{\alpha}} \bar{\alpha}\end{array}$ & $\tilde{\sigma}$ & $\tilde{\sigma}$ & $\tilde{\sigma}$ & $\begin{array}{l}\tilde{\sigma} \\
\tilde{\sigma}\end{array}$ \\
\hline$\underline{\underline{\infty}} \stackrel{\infty}{\bar{N}}$ & 苫 & 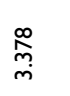 & 今్ & & đ̊ & లొ & $\stackrel{\$}{\$}$ & 䓵 & 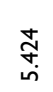 & 今े & مِ & $\stackrel{\infty}{\stackrel{\infty}{m}}$ & 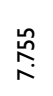 & 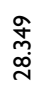 & 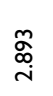 & 品 & $\stackrel{N}{N}^{\circ}$ & స్ & 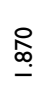 & 学 \\
\hline
\end{tabular}

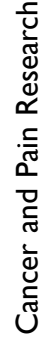

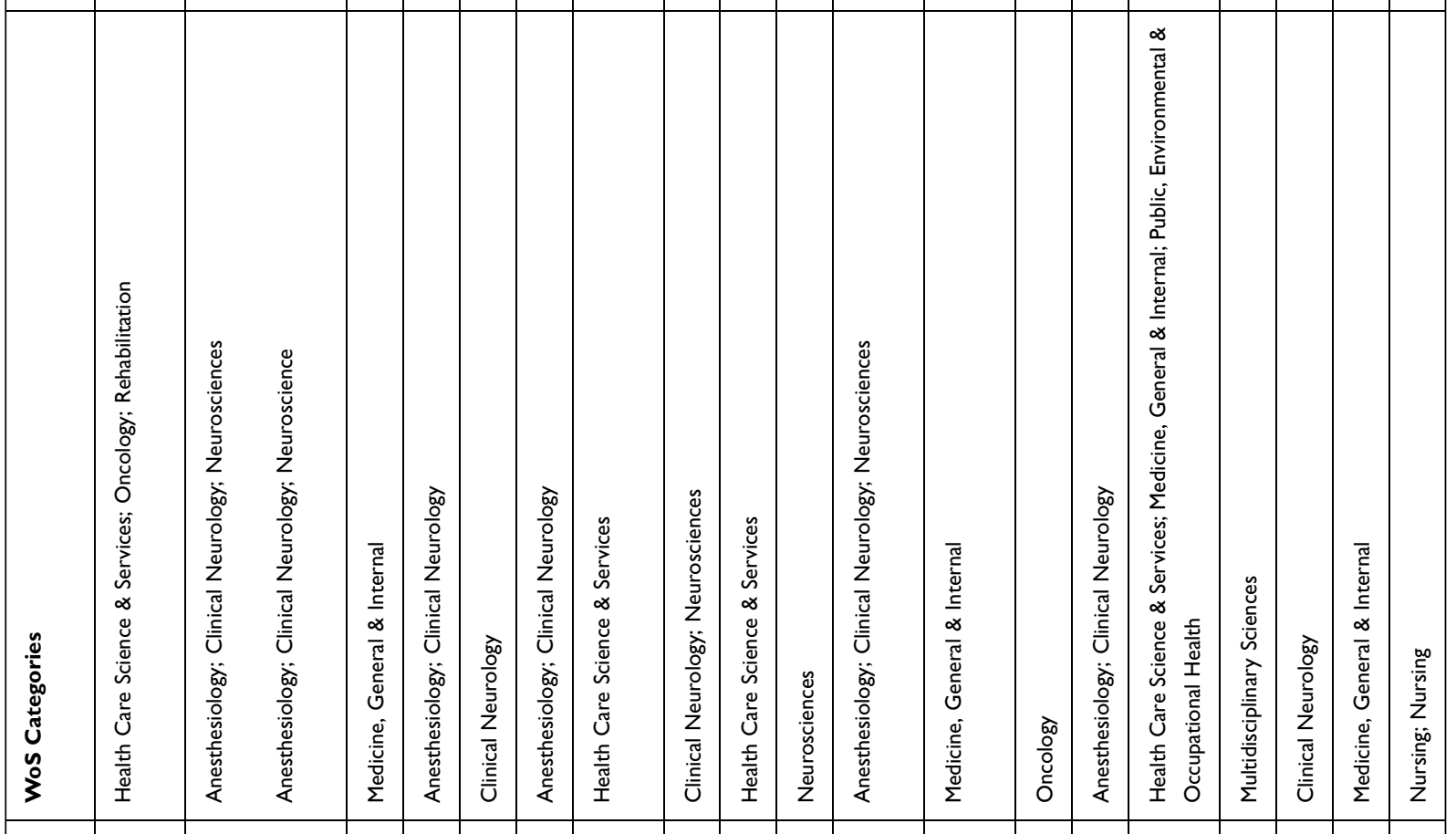

(20)

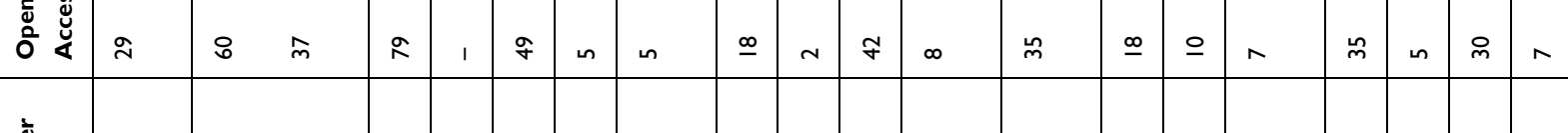

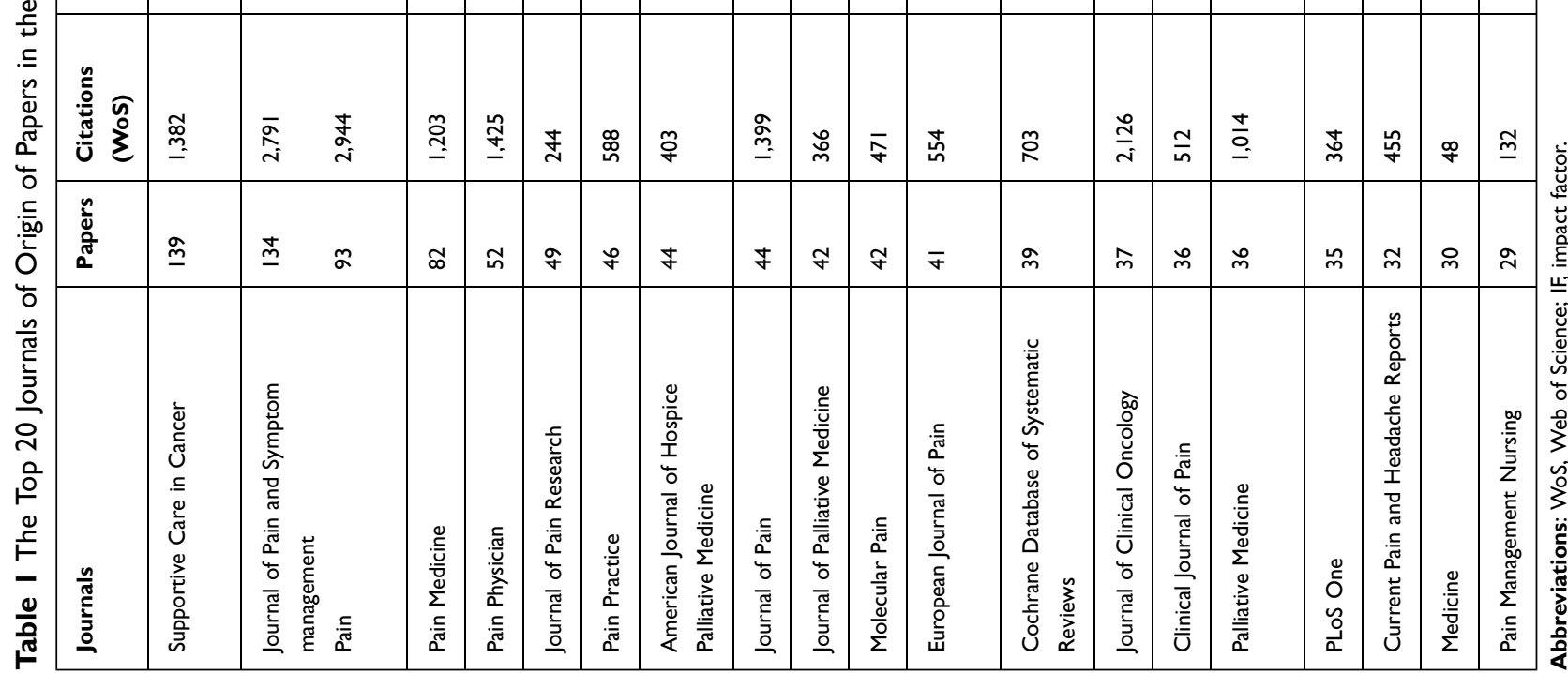




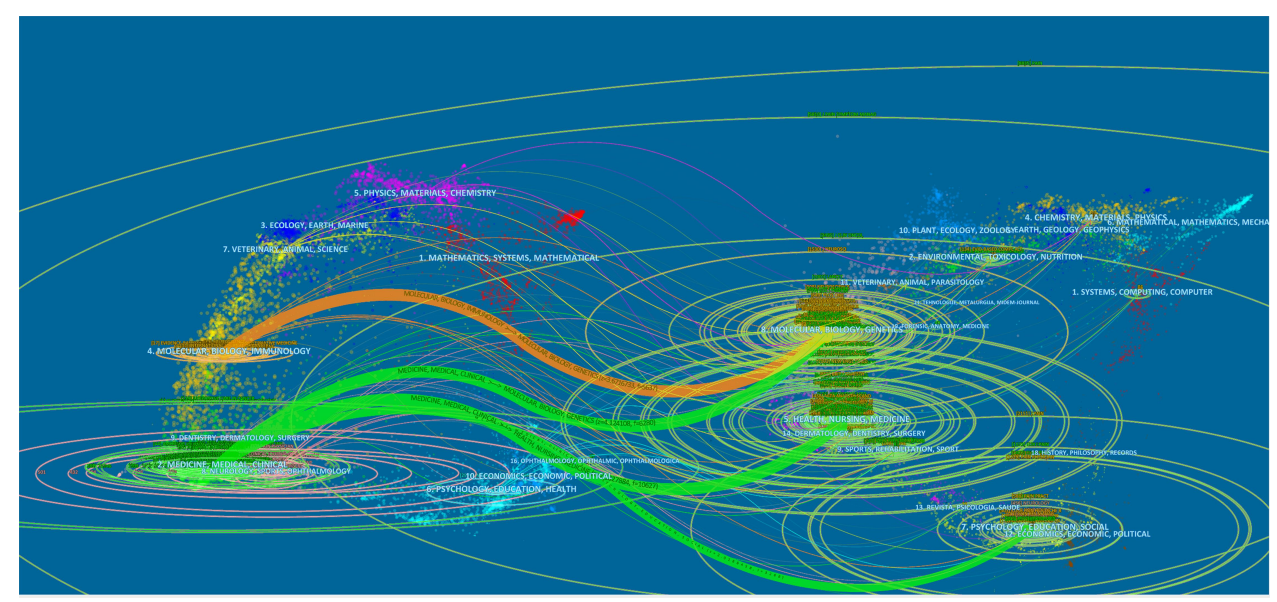

Figure 3 The dual-map overlay of journals related to cancer and pain research.

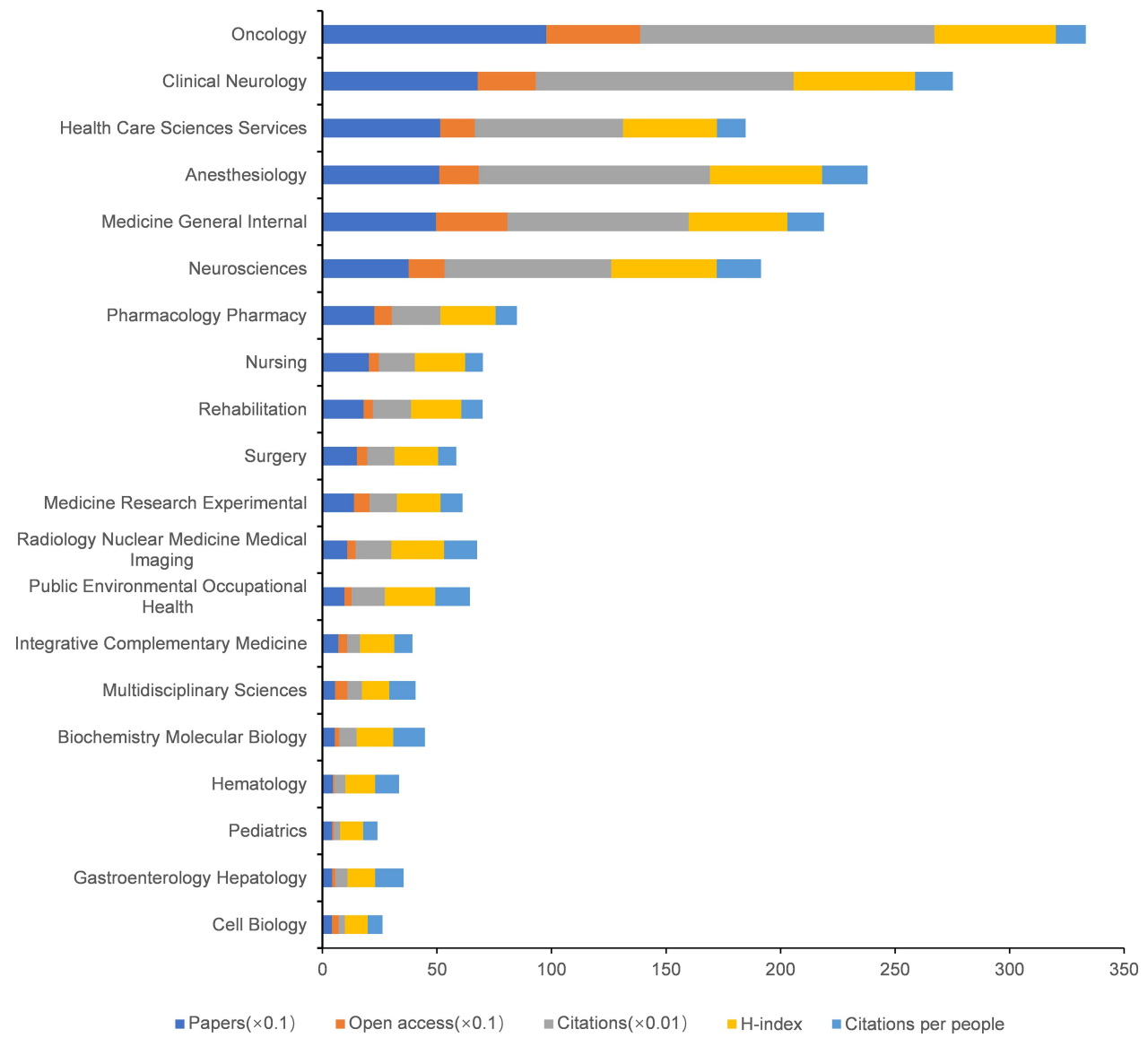

Figure 4 The number of papers, citations, citations per paper, open access papers, and $\mathrm{H}$-index of the top 20 subject categories of Web of Science.

publications) and oral cancer (397 publications). Regarding the topics that had the highest number of citation frequency, the largest quantity of citations per paper, and highest value of $\mathrm{H}$-index, breast cancer ranked the first, with 9,715 citations, 346 open access papers, 14 citations per paper, and an $\mathrm{H}$-index value of 51 , followed by bone cancer (7,555 citations, 315 open access papers, 14 citations per paper, and an H-index 


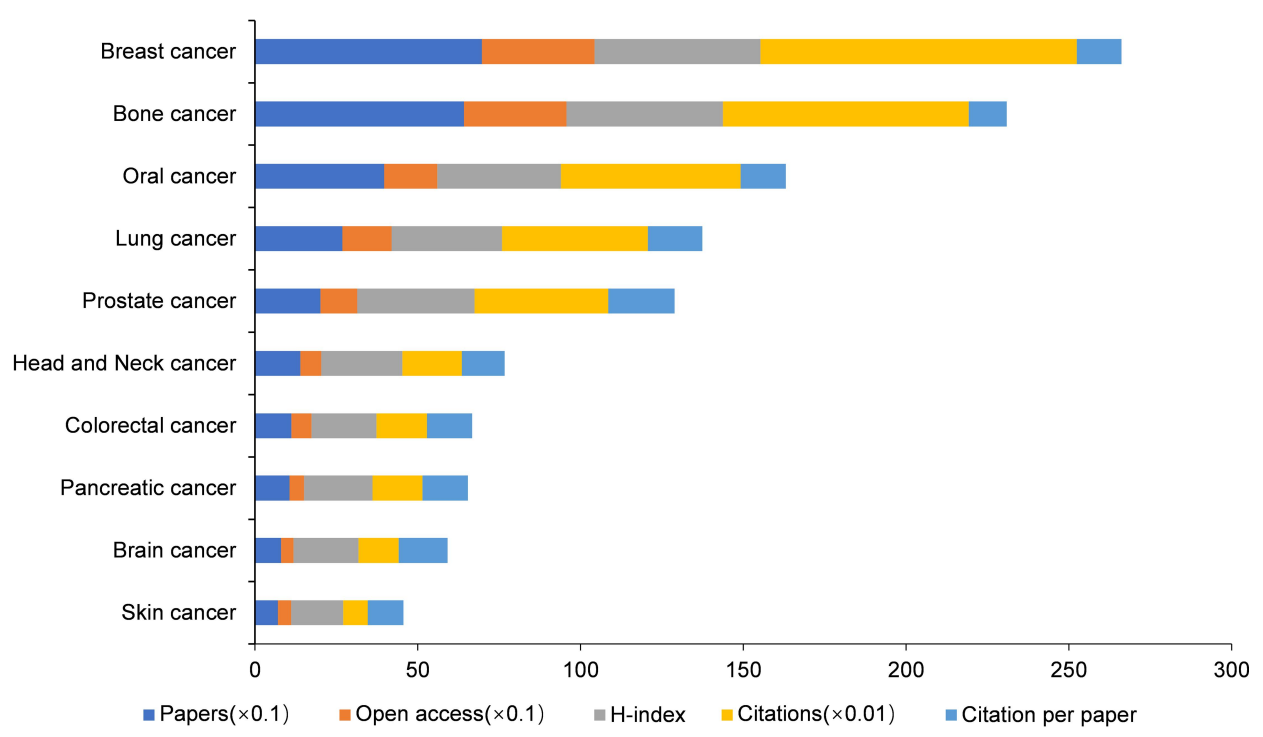

Figure 5 The number of papers, citations, citations per paper, open access papers, and value of $\mathrm{H}$-index of the top 10 types of cancer.

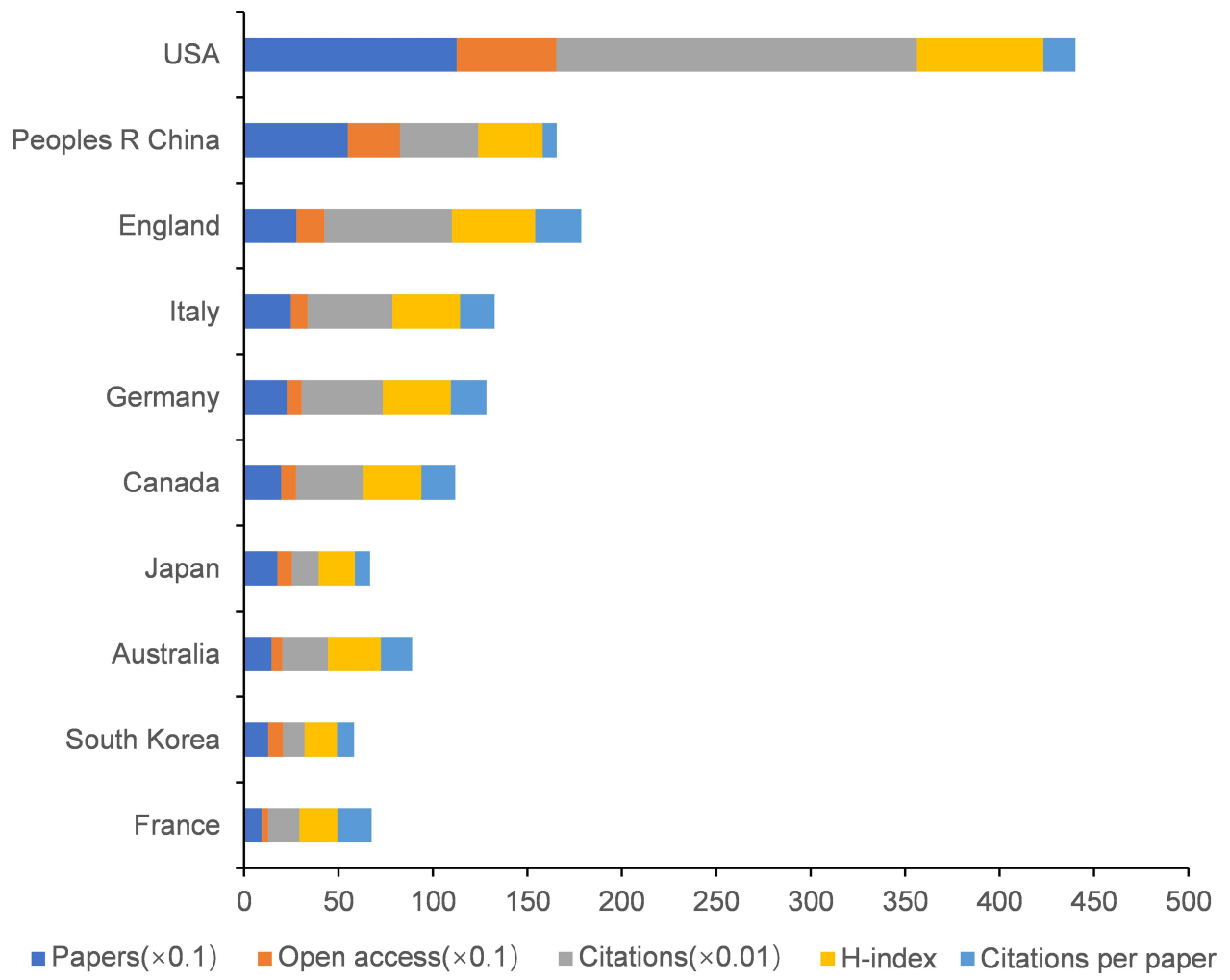

Figure 6 The number of papers, citations, citations per paper, open access papers and $\mathrm{H}$-index of the top 10 countries.

value of 48). The feedback indicated that the percentages of the annual publication count had a remarkable increase from 2010 to $2019(P<0.001)$ in breast cancer, bone cancer, spinal cancer, lung cancer, colorectal cancer, brain cancer, and skin cancer.

\section{Analysis of Countries and Institution Distribution}

The results were contributed by 68 countries/territories, as shown in Supplementary Table 2. Considering the quantity of papers, we listed the top 10 countries/ 
A

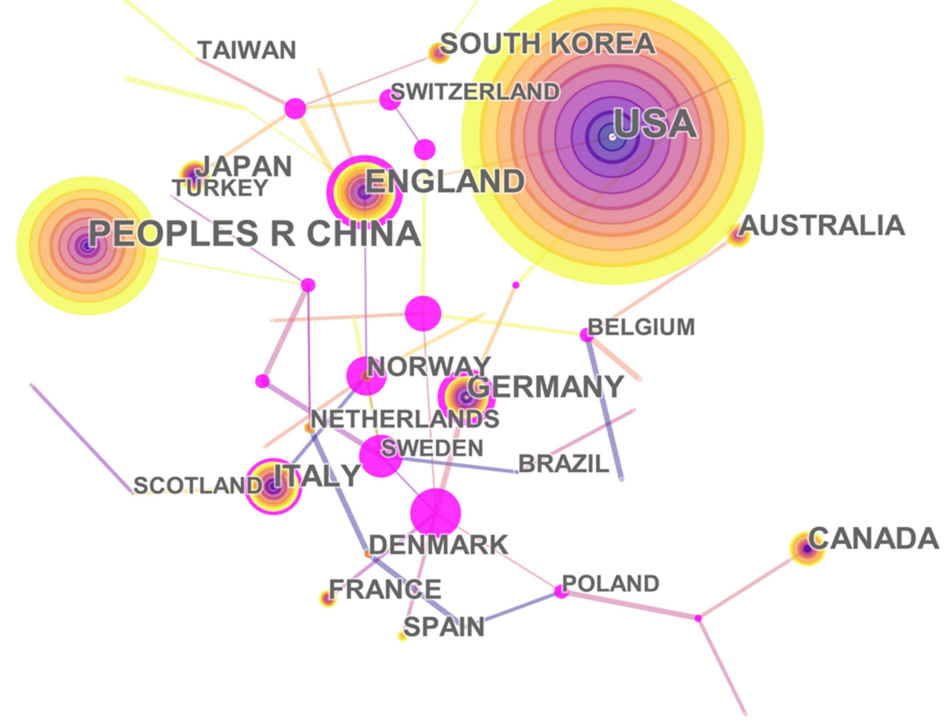

B

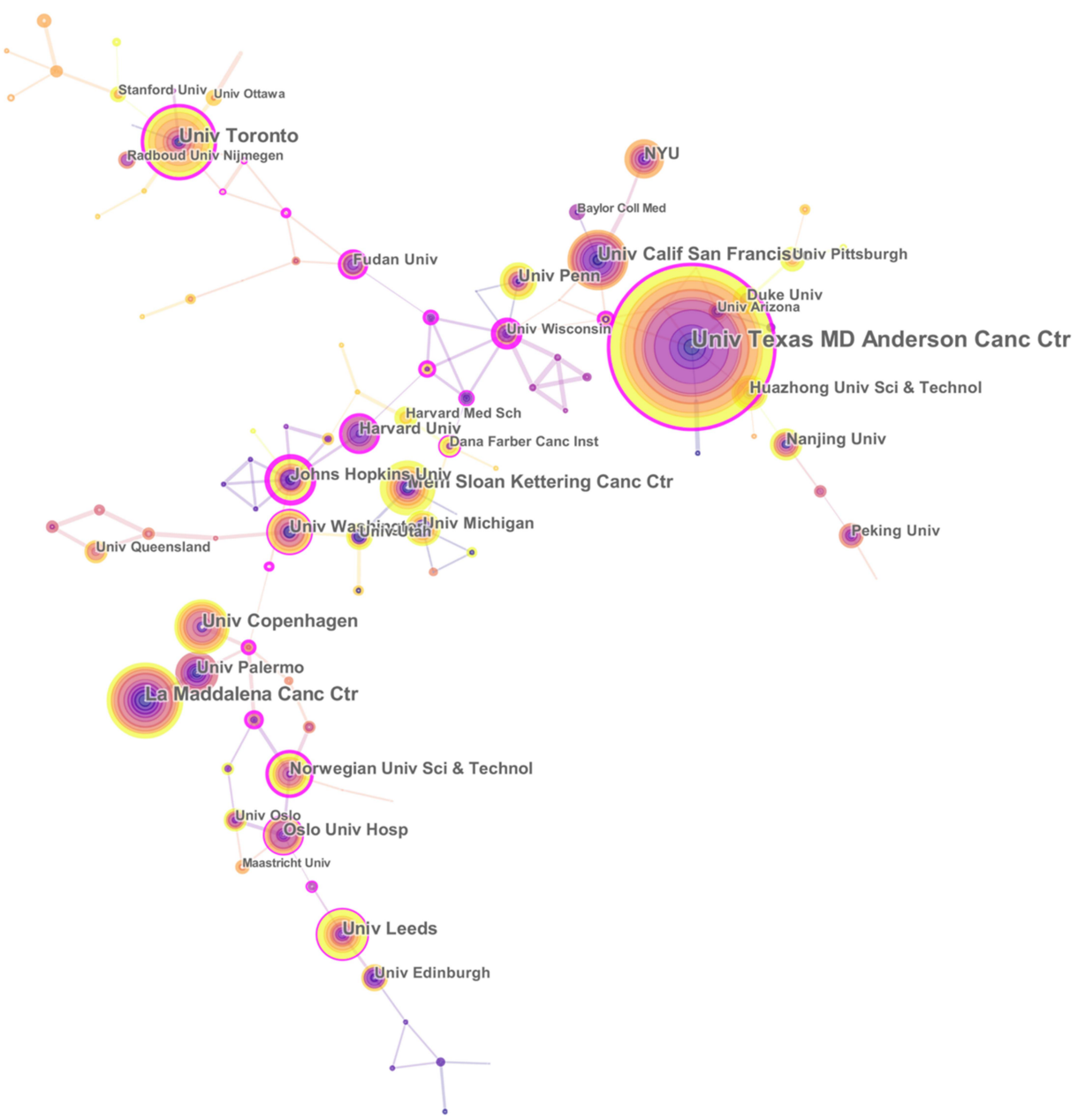

Figure 7 The analysis of countries and institutions. (A) Network map of countries/territories engaged in cancer and pain research. (B) Network map of institutions engaged in cancer and pain research. 


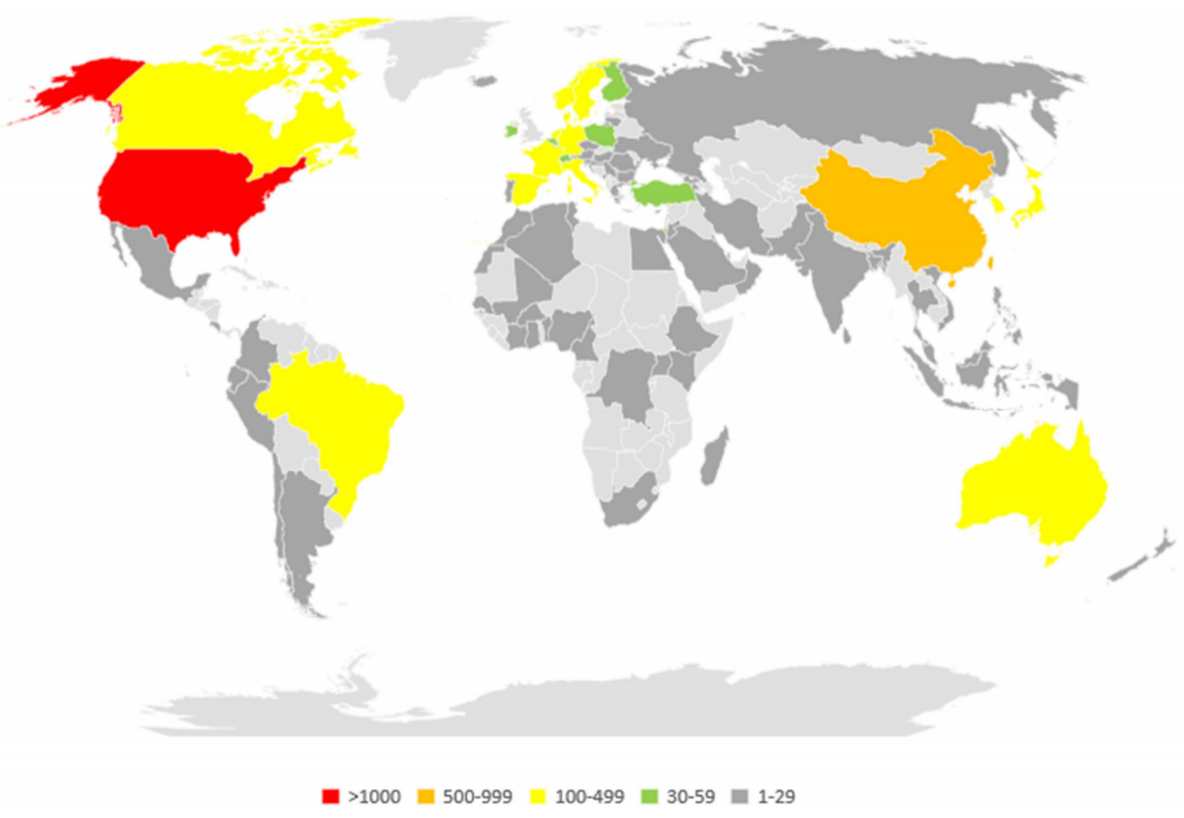

Figure 8 World map of total country output based on cancer and pain research.

territories (Figure 6). As a result, the US has made the highest contribution regarding the comorbidity of cancer and pain, which had the largest quantity of papers $(1,126)$, largest number of citations $(19,097)$, largest quantity of open access papers (526), and highest H-index value (67), followed by China (549 papers, 4,146 citations, 276 open access papers, and H-index value of 34), England (276 papers, 6759 citations, 148 open access papers, and an H-index value of 44), and Italy (247 papers, 4,488 citations, 88 open access papers, and an $\mathrm{H}$-index value of 36 ). And the expansive co-operation of the countries/institutions is shown in Figure 7. We also mapped the world map to present the overview of all countries according to published quantity, as shown in Figure 8. The top 10 institutions were selected and listed by the number of publications from 3,749 institutions (Supplementary Table 3) that contributed to the comorbidity of cancer and pain (Supplementary Figure 1), and the proportion of contributions reached up to $16.77 \%$. In detail, The University of Texas MD Anderson Cancer Center had the highest quantity of papers (121), citations $(2,971)$, open access papers (50), and H-index value (31). The University of Leeds made the highest contribution in the quantity of citations per paper (28.9).

\section{Distribution by Authors}

As many as 14,646 authors have contributed to the comorbidity cancer and pain. To determine the collaboration among authors, we mapped the network map (Figure 9). As shown in Table 2, S. Mercadante had the highest number of publications (69) and citations (717). The author with the highest citation frequency was A. Caraceni. The general trend of the percentages of single-authored papers decreased from $7.18 \%$ in 2010 to $4.12 \%$ in 2019, as shown in Figure 10. According to the feedback of the linear regression analyses, the percentage trend of single-authored papers significantly decreased. Meanwhile, the percentage trend of multiple-authored papers ( $\geq 2$ ) significantly increased from 2010 to 2019 $(\mathrm{t}=2.808, P<0.05)$.

\section{Analysis of References}

The concept of co-citation references is utilized as a research method to assess the degree of relationship between publications and considered as an important indicator in bibliometric studies. The scientific correlation of the published papers was presented in the cocitation map of the references (Figure 11). All 13 major clusters had a mean silhouette of 0.9593 , which was higher than 0.5 . This result indicated a high-quality 


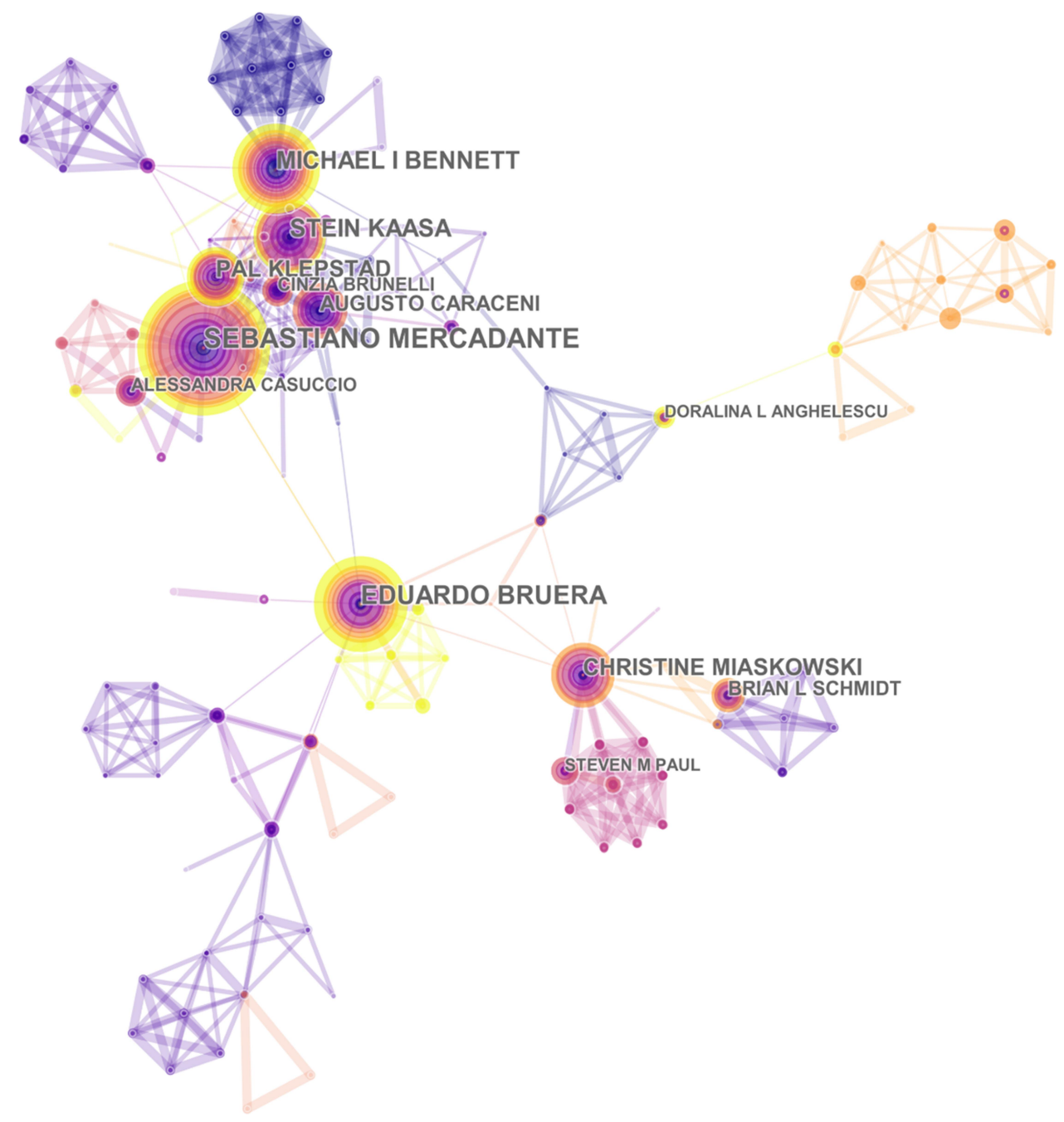

Figure 9 The analysis of authors. Network map of active authors that contributed to cancer and pain research.

cluster analysis of the network map. Figure 12 shows 13 major clusters presented in a time view. The cluster that ranked first was neoplasms (\#0), followed by neoplasm pain. ${ }^{26}$ These clusters contained neoplasms that are predominant in studies on the comorbidity of cancer and pain over time. The cluster that ranked third was bone cancer. $^{27}$

\section{Analysis of Keywords}

We used CiteSpace $(5,5, \mathrm{R} 2)$ to extract the keywords on the comorbidity of cancer and pain. As shown in Figure 12, the top 36 keywords with the strongest citation bursts by the start of 2011 were as follows: "TNF- $\alpha$ ", "Pharmacokinetics", "Transdermal fentanyl", and "Lung cancer", and the keywords ending in 2019 included "Outcome" (2017-2019),
“Oncology” (2017-2019), “Activation” (2017-2019), and "Inflammation” (2017-2019).

\section{Analysis of Highest Number of Citation Frequency of Papers}

The top 10 papers with the highest citation frequency on the comorbidity of cancer and pain are shown in Table 3. According to the quantity of citations of publications on the achievements of the comorbidity of cancer and pain, the top 10 papers with the largest number of citations accounted for $31.55 \%$. The proportion of the number of citations of the top 10 papers in the total number of citations was up to $5.37 \%$. The article entitled "Use of opioid analgesics in the treatment of cancer pain: evidence-based recommendations from the EAPC," which was written by Caraceni et $\mathrm{al}^{28}$ and 
Table 2 The Top 10 Authors, Co-Cited Authors, and Co-Cited References in the Anxiety and Pain Research

\begin{tabular}{|c|c|c|c|c|c|}
\hline Author & $\begin{array}{l}\text { Published } \\
\text { Articles }\end{array}$ & Co-Cited Author & $\begin{array}{l}\text { Cited } \\
\text { Times }\end{array}$ & Co-Cited Reference & $\begin{array}{l}\text { Cited } \\
\text { Times }\end{array}$ \\
\hline Mercadante S & 69 & Mercadante S & 717 & Caraceni A, 2012 Lancet Oncol, VI3, P0 & 220 \\
\hline Bruera $\mathrm{E}$ & 45 & Portenoy RK & 547 & Everdingen M, 2007, Ann Oncol, VI8, PI437 & 210 \\
\hline Kaasa S & 45 & Caraceni A & 492 & Deandrea S, 2008, Ann Oncol, VI9, PI985 & 169 \\
\hline Bennett Mi & 43 & Cleeland CS & 484 & Breivik H, 2009, Ann Oncol, V20, PI420 & 143 \\
\hline Klepstad P & 37 & Everdingen $M$ & 425 & $\begin{array}{l}\text { Van Den B, 2016, J Pain Symptom Manag, V5I, } \\
\text { PI070 }\end{array}$ & 119 \\
\hline Caraceni A & 36 & Anonymous & 379 & Davies An, 2009,Eur J Pain, VI3, P33 I & 109 \\
\hline $\begin{array}{l}\text { Miaskowski } \\
\text { C }\end{array}$ & 33 & Deandrea & 291 & Portenoy RK, 20II, Lancet, V377, P2236 & 94 \\
\hline Radbruch L & 24 & Breivik $\mathrm{H}$ & 281 & Andersen KG, 20II, J Pain, VI2, P725 & 91 \\
\hline Schmidt BL & 24 & Bruera $\mathrm{E}$ & 244 & Ripamonti Cl, 20I2, Ann Oncol, V23, PI39 & 84 \\
\hline Zhang J & 23 & $\begin{array}{l}\text { World Health } \\
\text { Organization }\end{array}$ & 229 & Greco MT, 20I4, J Clin Oncol, V32, P4I49 & 72 \\
\hline
\end{tabular}

published in Lancet Oncology, had the highest number of citation frequencies (585 citations). Table 3 shows that six reports $^{28-33}$ were published in journals with IF $\geq 10$ (Lancet Oncology, Lancet, Annals of Oncology), two papers ${ }^{34,35}$ in journals with $3 \leq \mathrm{IF}<5$ (Journal of Pain and Symptom Management, Current Medical Research), and two works $^{36,37}$ in a journal with $1 \leq \mathrm{IF}<3$ (Pain Physician and Current Medical Research and Opinion). The data sources are from Journal Citation Reports (2018 edition).

\section{Discussion}

\section{Global Potential and Achievement}

This bibliometric study presented a visual and systematic review of the comorbidity of cancer and pain with every

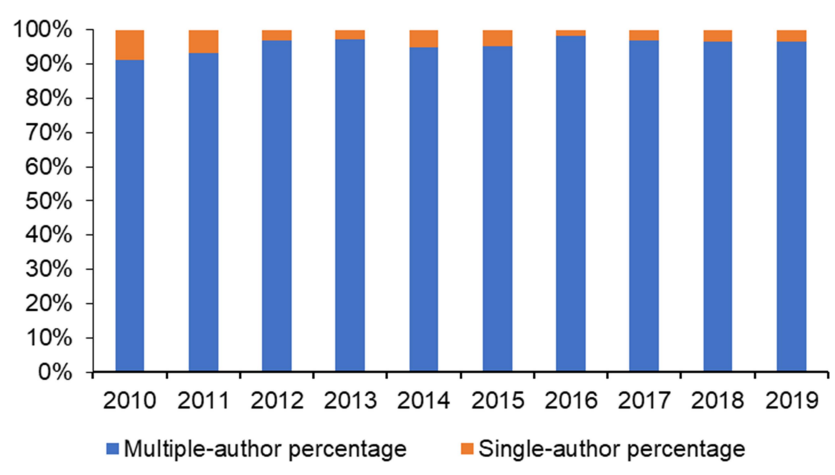

Figure 10 Trends in the percentage of single- vs multiple-authored articles per years. related article from WOS from 2010-2019. In the last 10 years, the global trends of the number of publications has been growing continually year by year. Four stages were presented on the development trend of quantity of papers on the comorbidity of cancer and pain studies: two slow increase speeds were observed from 2010-2012 and from 2013-2018, and two remarkable increases were shown from 2012-2013 and from 2018-2019. In 2019, the quantity of papers reached up to 442 , the number of citations reached up to 8,649 , and the H-index value was 50 . On the basis of the quantity of papers on the achievements of the comorbidity of cancer and pain, the top 20 journals with the largest number of publications accounted for $31.55 \%$. Supportive Care in Cancer had the largest quantity of papers (4.03\%), followed by Pain and Symptom Management (3.89\%), Pain (2.70\%), and Pain Medicine (2.38\%). Among the top 20 journals with IF $>10$ (Oncology, IF: 28.349), six had $1 \leq \mathrm{IF}<3$, two had $3 \leq \mathrm{IF}<5$, and two had $5 \leq \mathrm{IF}<10$. According to the quantity of papers, the US ranked first in the quantity of papers $(1,126)$, followed by China (543), England (276), and Italy (247). Among the top 10 countries/territories, four were located in Europe, three in Asia, two in North America, and one in Oceania. The clear expansive co-operation of countries/institutions is presented in Figure 7. Based on the top 10 institutions with the highest number of publications, five were from the US, one from England, one from Italy, one from Norway, one from Denmark, and one from Toronto. 


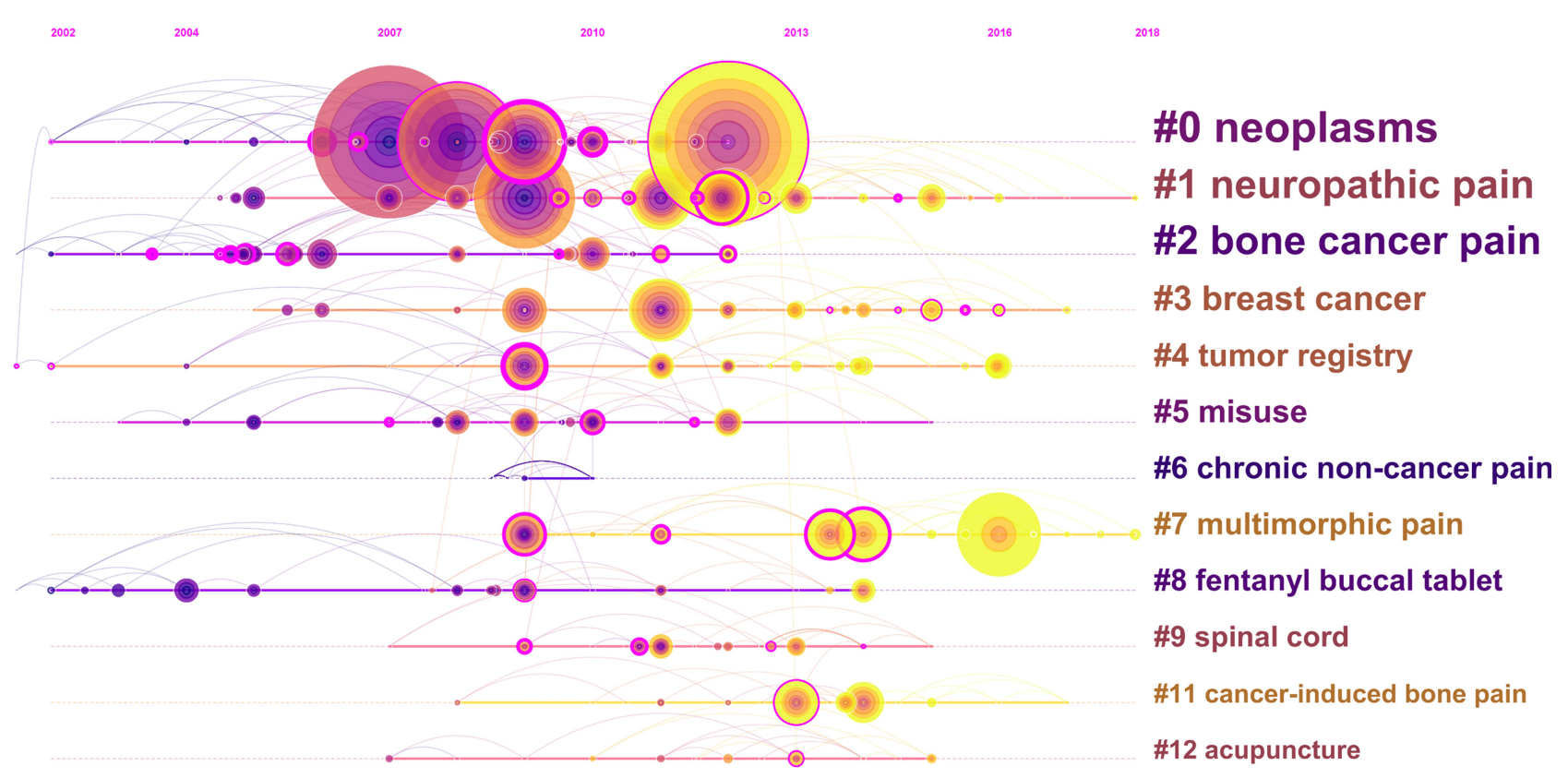

Figure II The analysis of references. Co-citation map (timeline view) of references from publications on to cancer and pain research.

\section{Research Energy and Potential}

In the last decade, in terms of the popularity of research subject categories of WOS, the comorbid cancer and pain research has mainly concentrated on Oncology (978, publications), followed by Clinical Neurology (877, publications), Health Care Sciences Services (514, publications), Anesthesiology (510, publications), and Surgery. In terms of research topics, 697 papers focused on breast cancer, which accounted for $20.36 \%$ of the 3,423 publications that are related to the comorbidity of cancer and pain. The top 10 types of cancer were breast cancer, bone cancer, oral cancer, lung cancer, prostate cancer, colorectal cancer, brain cancer, and skin cancer. According to the co-citation map of references, in the past 10 years, the majority of research mainly focused on "neoplasms" (\#0) and "neoplasm pain". ${ }^{26}$ Meanwhile, "bone cancer pain"27 and "breakthrough pain" ${ }^{38}$ have drawn considerable attention. The study of $\mathrm{Zhu}$ et $\mathrm{al}^{39}$ focused on the progress of cancer pain from bone metastasis, mechanisms involved in cancer pain, and drug treatment of cancer pain in animal models. Breakthrough cancer pain (BTcR) refers to high-intensity, short-duration pain that occurs several times a day without effective therapy. ${ }^{40}$ Meanwhile, the study of Hagen et $\mathrm{al}^{41}$ showed novel approaches to pain management to identify several innovative strategies for BTcR. The research of Furio et $\mathrm{al}^{40}$ shared that a reasonable synthesis of the unremitting $\mathrm{BTcP}$ scientific discussed by clinicians and practitioners and a basis for optimal clinical approach. According to the top 36 keywords with the strongest citation bursts, the results in 2010 were as follows: "TNF-alpha," "Pharmacokinetics", "Transdermal fentanyl", and "Lung cancer". The keywords at the end of 2019 were as follows: "Survival" (2015-2019), "Recommendation" (2017-2019), "Persistent pain" (2016-2019), "Survivor" (2016-2019), "Meta-analysis" (2016-2019), "Outcome" (2017-2019), “Oncology" (2017-2019), “Activation" (2017-2019), and "Inflammation" (2017-2019). In the last 10 years, with the technological developments in cancer diagnosis and therapy, the rates of survivors with cancer are increasing The issue of making certain how to improve the life quality of patients with cancer has aggregated a number of common concerns. In terms of an effective method to relieve cancer pain, Gong et $\mathrm{al}^{42}$ demonstrated that 3 -elemene has an ideal effect in relieving pain behavior in a rat model of BCRP. 


\section{Top 36 Keywords with the Strongest Citation Bursts}

\begin{tabular}{|c|c|c|c|c|c|}
\hline Keywords & Year & Strength & Begin & End & $2010-2019$ \\
\hline TNF alpha & 2010 & 8.9666 & 2010 & 2011 & \\
\hline Pharmacokinetics & 2010 & 10.0241 & 2010 & 2011 & \\
\hline Transdermal fentanyl & 2010 & 9.4953 & 2010 & 2011 & \\
\hline Lung cancer & 2010 & 6.5577 & 2010 & 2011 & \\
\hline Health & 2010 & 8.2209 & 2010 & 2013 & \\
\hline Murine model & 2010 & 9.5958 & 2010 & 2013 & \\
\hline Breakthrough pain & 2010 & 3.7264 & 2010 & 2011 & \\
\hline Receptor & 2010 & 3.4911 & 2010 & 2012 & \\
\hline Neoplasm & 2010 & 12.67 & 2010 & 2011 & \\
\hline Open label & 2010 & 7.5922 & 2011 & 2012 & \\
\hline Randomized trial & 2010 & 8.9681 & 2011 & 2012 & \\
\hline Disease & 2010 & 10.0257 & 2011 & 2012 & \\
\hline Oxycodone & 2010 & 10.5547 & 2011 & 2012 & \\
\hline Bone metastasis & 2010 & 9.3629 & 2011 & 2014 & \\
\hline Low back pain & 2010 & 9.7745 & 2011 & 2013 & \\
\hline Rat model & 2010 & 9.2403 & 2012 & 2016 & \\
\hline Safety & 2010 & 10.0254 & 2013 & 2016 & \\
\hline Fentanyl & 2010 & 6.9628 & 2013 & 2015 & \\
\hline Hyperalgesia & 2010 & 5.2761 & 2014 & 2015 & \\
\hline Model & 2010 & 7.0674 & 2014 & 2015 & \\
\hline Attitude & 2010 & 11.4752 & 2014 & 2015 & \\
\hline Multicenter & 2010 & 10.2264 & 2014 & 2016 & \\
\hline Outpatient & 2010 & 8.8284 & 2014 & 2015 & \\
\hline Survival & 2010 & 6.4941 & 2015 & 2019 & \\
\hline Chemotherapy & 2010 & 6.9991 & 2015 & 2017 & \\
\hline Questionnaire & 2010 & 5.8072 & 2015 & 2017 & \\
\hline Recommendation & 2010 & 3.4307 & 2016 & 2019 & \\
\hline Persistent pain & 2010 & 12.988 & 2016 & 2019 & \\
\hline Prostate cancer & 2010 & 4.5116 & 2016 & 2017 & $=$ \\
\hline Survivor & 2010 & 16.9702 & 2016 & 2019 & \\
\hline Meta-analysis & 2010 & 16.9878 & 2016 & 2019 & \\
\hline Outcome & 2010 & 7.921 & 2017 & 2019 & \\
\hline United States & 2010 & 13.2697 & 2017 & 2019 & \\
\hline Oncology & 2010 & 4.8224 & 2017 & 2019 & \\
\hline Activation & 2010 & 7.5705 & 2017 & 2019 & \\
\hline Inflammation & 2010 & 13.0688 & 2017 & 2019 & \\
\hline
\end{tabular}

Figure 12 The keywords with the strongest citation bursts of publications on cancer and pain research.

\section{Strengths and Limitations}

The main strength was that this bibliometric study assessed the global trends on the study on the comorbidity of cancer and pain between 2010 and 2019. The data of this bibliometric study were extracted from the SCI-Expended of Web of Science Core database, which is highly credible and reliable. The above results indicated that the publications retrieved were published in more than 841 academic journals, which contributed to the abundance of the centralized publications. Given that other electronic databases were not retrieved, a research bias may be present. Given that various potential influential publications have been published recently, a comparatively small number of citations of papers can be as important as large citations of papers. Finally, the inherent limitations of bibliometric tools in the assessment of research output and/or impact should be considered. 


\begin{tabular}{|c|c|c|c|c|c|c|c|c|c|c|}
\hline 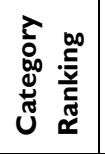 & 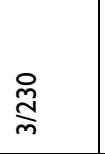 & $\stackrel{\circ}{i}$ & 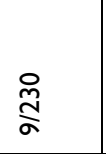 & $\stackrel{\circ}{i}$ & 菂 $\frac{a}{\sigma}$ & 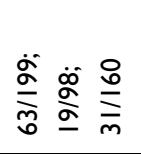 & $\stackrel{\stackrel{O}{N}}{m}$ & 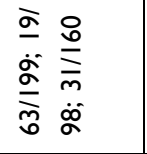 & $\stackrel{\stackrel{\overbrace{}}{N}}{m}$ & $\begin{array}{l}\text { ㄱ } \\
\ddot{0} \\
\stackrel{0}{=} \stackrel{0}{n}\end{array}$ \\
\hline 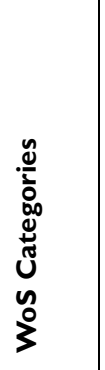 & 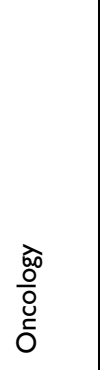 & 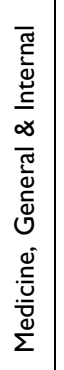 & 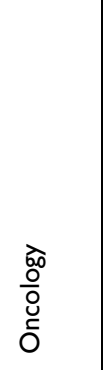 & 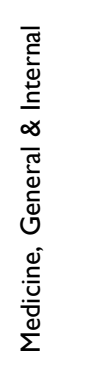 & 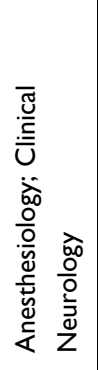 & 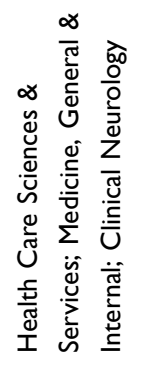 & 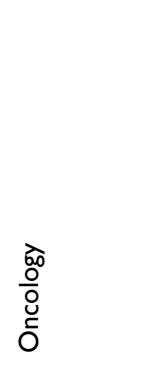 & 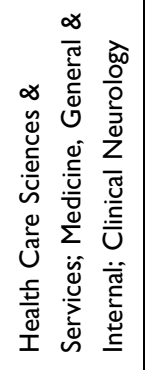 & 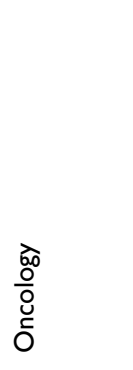 & 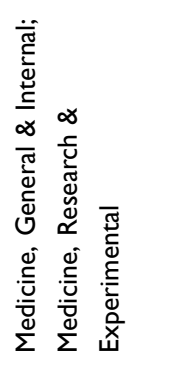 \\
\hline 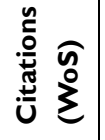 & $\stackrel{\leftrightarrow}{\infty}$ & $\stackrel{\mathbb{\sim}}{\sim}$ & $\stackrel{\widehat{J}}{\sim}$ & $\stackrel{\infty}{\underset{\sim}{*}}$ & సิ & $\frac{n}{N}$ & 㝏 & ¿ั & ঃ্ণ & $\underline{\sigma}$ \\
\hline 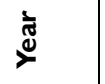 & $\stackrel{\sim}{\stackrel{\sim}{2}}$ & $\overline{\bar{N}}$ & $\stackrel{\sim}{\circ}$ & $\overline{\bar{i}}$ & $\stackrel{\sim}{\grave{N}}$ & $\stackrel{\circ}{\stackrel{\sim}{\alpha}}$ & $\overline{\bar{i}}$ & 음 & 윰 & $\overline{\bar{i}}$ \\
\hline 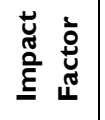 & 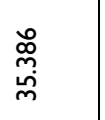 & $\frac{\tilde{\delta}}{i n}$ & $\frac{\stackrel{\circ}{\dot{I}}}{\dot{+}}$ & $\frac{\tilde{\delta}}{\sigma}$ & İ & $\underset{\substack{\infty \\
m}}{\stackrel{\infty}{m}}$ & $\underset{m}{\stackrel{\infty}{m}}$ & $\underset{m}{\stackrel{\infty}{m}}$ & 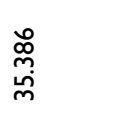 & 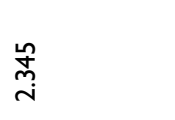 \\
\hline 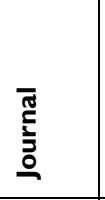 & 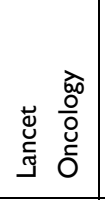 & 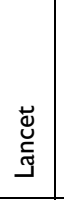 & 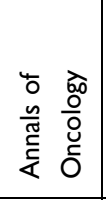 & $\begin{array}{l}\text { ّ̆ } \\
\text { ज̃ } \\
\end{array}$ & 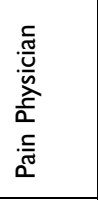 & 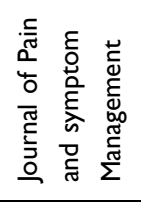 & 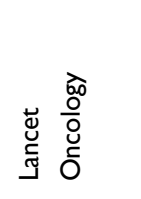 & 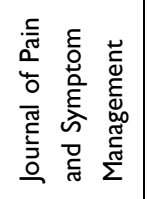 & 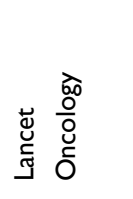 & 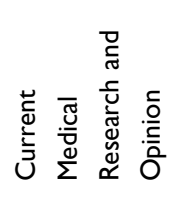 \\
\hline 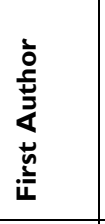 & 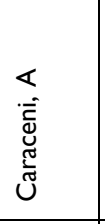 & 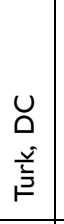 & 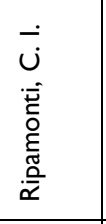 & 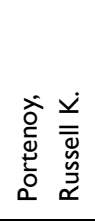 & 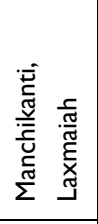 & 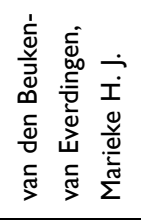 & 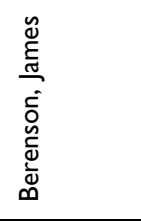 & 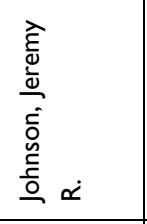 & 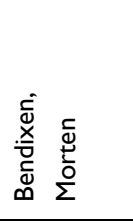 & $\begin{array}{l}\dot{\vec{g}} \\
\dot{\underline{\underline{y}}} \\
\dot{\bar{g}} \\
\mathscr{Q}\end{array}$ \\
\hline$\stackrel{0}{ \pm}$ & 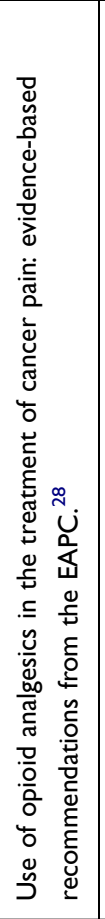 & 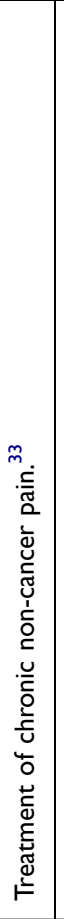 & 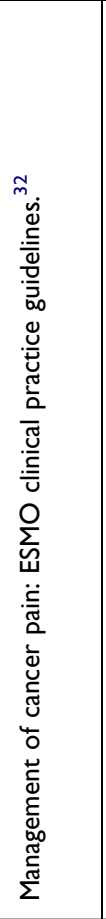 & 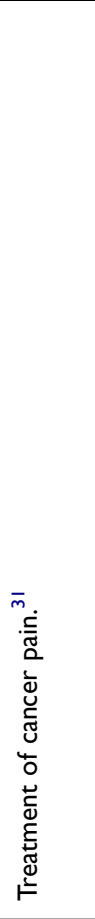 & 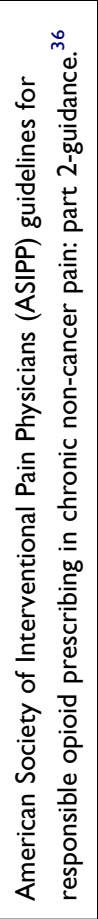 & 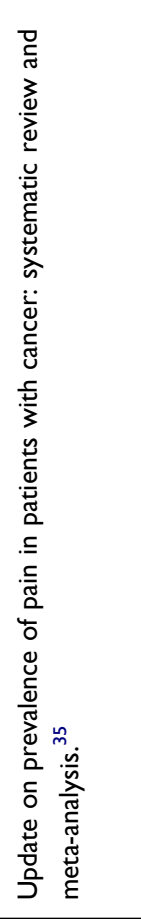 & 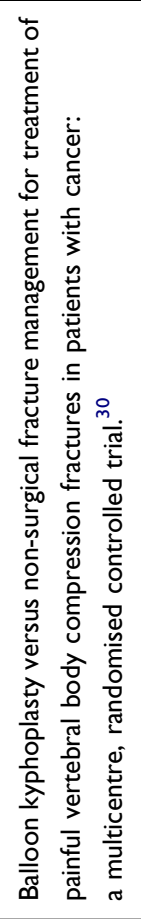 & 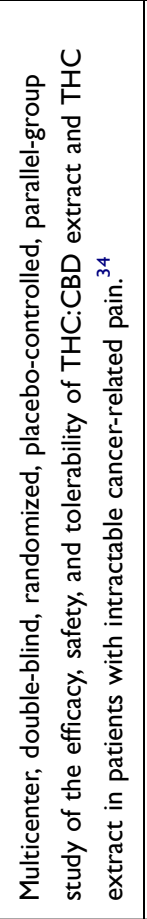 & 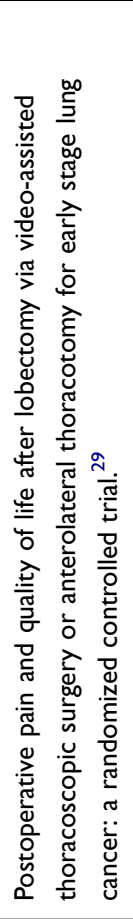 & 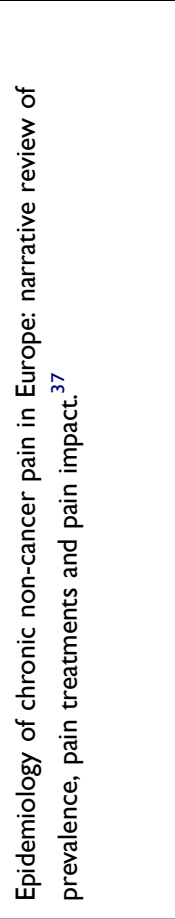 \\
\hline
\end{tabular}




\section{Conclusion}

The area of the comorbidity cancer and pain is rich in potential and energy, and this paper provides an insight into this promising research field. Meanwhile, this paper has various limitations. The quantity of papers related to the comorbidity of cancer and pain showed a remarkable growth over time (from 259 in 2010 to 452 in 2019). According to the co-citation map of the reference, the research was primarily focused on neoplasms, neoplasm pain, bone cancer pain, and breakthrough pain, which were in favor of offering knowledge to relevant founding agencies and policymakers. The finding of this paper lays the framework for future development of research on the comorbidity of cancer and pain.

\section{Funding}

This work was supported by the Shanghai Key Lab of Human Performance (Shanghai University of Sport) (11DZ2261100); The scientific and technological research program of the Shanghai Science and Technology Committee (Fund number: 19080503100).

\section{Disclosure}

The authors report no conflicts of interest in this work.

\section{References}

1. Solvik E, Ytrehus S, Utne I, Grov EK. Pain, fatigue, anxiety and depression in older home-dwelling people with cancer. Nursing Open. 2020;7(1):430-438. doi:10.1002/nop2.406

2. Xie F, You Y, Huang J, et al. Association between physical activity and digestive-system cancer: an updated systematic review and meta-analysis. J Sport Health Sci. 2020;30(20):S2095-2546.

3. Xu T, Lei H, Zhang Y, et al. Interventions for cancer-related pain: protocol of an umbrella systematic review and network meta-analysis. Medicine (Baltimore). 2019;98(45):e17844.

4. Vainshelboim B, Lima RM, Myers J. Cardiorespiratory fitness and cancer in women: a prospective pilot study. J Sport Health Sci. 2019;8(5):457-462.

5. Mariotto AB, Yabroff KR, Shao Y, Feuer EJ, Brown ML. Projections of the cost of cancer care in the United States: 2010-2020. J Natl Cancer Inst. 2011;103(2):117-128.

6. Liou KT, Hung TKW, Meghani SH, et al. What if acupuncture were covered by insurance for pain management? A cross-sectional study of cancer patients at one academic center and 11 Community Hospitals. Pain Med. 2019;20(10):2060-2068.

7. Breivik H, Cherny N, Collett B, et al. Cancer-related pain: a pan-European survey of prevalence, treatment, and patient attitudes. Ann Oncol. 2009;20(8):1420-1433.

8. Dahlhamer J, Lucas J, Zelaya C, et al. Prevalence of chronic pain and high-impact chronic pain among adults - United States, 2016. MMWR Morb Mortal Wkly Rep. 2018;67(36):1001-1006.

9. Deandrea S, Montanari M, Moja L, Apolone G. Prevalence of undertreatment in cancer pain. A review of published literature. Ann Oncol. 2008;19(12):1985-1991.
10. Wang X-Q, Peng M-S, Weng L-M, et al. Bibliometric study of the comorbidity of pain and depression research. Neural Plast. 2019;2019:1657498. doi:10.1155/2019/1657498

11. Puetzler J, Feldmann RE Jr, Brascher A-K, Gerhardt A, Benrath J. Improvements in health-related quality of life by comprehensive cancer pain therapy: a pilot study with breast cancer outpatients under palliative chemotherapy. Oncol Res Treat. 2014;37 (9):456-462. doi:10.1159/000365537

12. Porter LS, Keefe FJ. Psychosocial issues in cancer pain. Curr Pain Headache Rep. 2011;15(4):263-270.

13. Schmidt BL. The neurobiology of cancer pain. J Oral Maxillofacial Surg. 2015;73(12 Suppl):S132-135.

14. Brown MR, Ramirez JD. Neuroimmune mechanisms in cancer pain. Curr Opin Support Palliat Care. 2015;9(2):103-111.

15. Zyoud SH, Fuchs-Hanusch D. A bibliometric-based survey on AHP and TOPSIS techniques. Expert Syst Appl. 2017;78:158-181.

16. Yang W, Hao X, Qu J, et al. Collaborative networks and thematic trends of research on the application of complementary and alternative medicine in cancer patients: a bibliometric analysis. Complement Ther Clin Pract. 2019;37:58-67.

17. Stout NL, Alfano CM, Belter CW, et al. A bibliometric analysis of the landscape of cancer rehabilitation research (1992-2016). J Natl Cancer Inst. 2018;110(8):815-824.

18. Ugolini D, Neri M, Cesario A, et al. Scientific production in cancer rehabilitation grows higher: a bibliometric analysis. Support Care Cancer. 2012;20(8):1629-1638.

19. Lu K, Yu S, Yu M, et al. Bibliometric analysis of tumor immunotherapy studies. Med Sci Monitor. 2018;24:3405-3414.

20. Moura LKB, Mobin M, Matos FTC, et al. Bibliometric analysis on the risks of oral cancer for people living with HIV/AIDS. Iran J Public Health. 2017;46(11):1583-1585.

21. Glynn RW, Chin JZ, Kerin MJ, Sweeney KJ. Representation of cancer in the medical literature-a bibliometric analysis. PLoS One. 2010;5(11):e13902.

22. Lewison G, Purushotham A, Mason M, McVie G, Sullivan R. Understanding the impact of public policy on cancer research: a bibliometric approach. Eur J Cancer. 2010;46(5):912-919.

23. Liang YD, Li Y, Zhao J, et al. Study of acupuncture for low back pain in recent 20 years: a bibliometric analysis via CiteSpace. J Pain Res. 2017;10:951-964.

24. Agarwal KK, Singla S, Arora G, Bal C. Lu-177-EDTMP for palliation of pain from bone metastases in patients with prostate and breast cancer: a Phase II study. Eur J Nucl Med Mol Imaging. 2015;42 (1):79-88.

25. Altundag K, Dizdar O, Ozsaran Z, et al. Phase II study of loading-dose ibandronate treatment in patients with breast cancer and bone metastases suffering from moderate to severe pain. Onkologie. 2012;35(5):254-258.

26. Sibley C, Ayers C, King B, Browning T, Kwon JK. Decreasing patient dwell times for outpatient cardiac nuclear medicine studies: the benefits of SMART goals, scope limitations, and society guidelines in quality improvement. Curr Probl Diagn Radiol. 2020;49 (5):333-336.

27. Takahashi PY, Quigg SM, Croghan IT, Schroeder DR, Ebbert JO. SMART goals setting and biometric changes in obese adults with multimorbidity: secondary analysis of a randomized controlled trial. SAGE Open Med. 2019;7:2050312119858042.

28. Caraceni A, Hanks GR, Kaasa S, et al. Use of opioid analgesics in the treatment of cancer pain: evidence-based recommendations from the EAPC. Lancet Oncol. 2012;13(2):E58-E68.

29. Bendixen M, Jorgensen OD, Kronborg C, Andersen C, Licht PB. Postoperative pain and quality of life after lobectomy via video-assisted thoracoscopic surgery or anterolateral thoracotomy for early stage lung cancer: a randomised controlled trial. Lancet Oncol. 2016;17(6):836-844. 
30. Berenson J, Pflugmacher R, Jarzem P, et al. Balloon kyphoplasty versus non-surgical fracture management for treatment of painful vertebral body compression fractures in patients with cancer: a multicentre, randomised controlled trial. Lancet Oncol. 2011;12 (3):225-235

31. Portenoy RK. Treatment of cancer pain. Lancet. 2011;377 (9784):2236-2247.

32. Ripamonti CI, Santini D, Maranzano E, et al. Management of cancer pain: ESMO clinical practice guidelines. Ann Oncol. 2012;23:139-154.

33. Turk DC, Wilson HD, Cahana A. Treatment of chronic non-cancer pain. Lancet. 2011;377(9784):2226-2235.

34. Johnson JR, Burnell-Nugent M, Lossignol D, et al. Multicenter, double-blind, randomized, placebo-controlled, parallel-group study of the efficacy, safety, and tolerability of THC:CBD extract and THC extract in patients with intractable cancer-related pain. J Pain Symptom Manage. 2010;39(2):167-179.

35. van den Beuken-van Everdingen MHJ, Hochstenbach LMJ, Joosten EAJ, Tjan-Heijnen VCG, Janssen DJA. Update on prevalence of pain in patients with cancer: systematic review and meta-analysis. J Pain Symptom Manage. 2016;51(6):1070.

36. Manchikanti L, Abdi S, Atluri S, et al. American Society of Interventional Pain Physicians (ASIPP) guidelines for responsible opioid prescribing in chronic non-cancer pain: part 2-guidance. Pain Phys. 2012;15(3):S67-S116.
37. Reid KJ, Harker J, Bala MM, et al. Epidemiology of chronic non-cancer pain in Europe: narrative review of prevalence, pain treatments and pain impact. Curr Med Res Opin. 2011;27 (2):449-462.

38. Hagen NA, Biondo P, Stiles C. Assessment and management of breakthrough pain in cancer patients: current approaches and emerging research. Curr Pain Headache Rep. 2008;12(4):241-248.

39. Zhu XC, Zhang JL, Ge CT, et al. Advances in cancer pain from bone metastasis. Drug Des Devel Ther. 2015;9:4239-4245.

40. Zucco F, Bonezzi C, Fornasari D. Breakthrough cancer pain (BTcP): a synthesis of taxonomy, pathogenesis, therapy, and good clinical practice in adult patients in Italy. Adv Ther. 2014;31(7):657-682.

41. Hagen NA, Biondo P, Stiles C. Assessment and management of breakthrough pain in cancer patients: current approaches and emerging research. Curr Pain Headache Rep. 2008;12(4):241-248.

42. Gong LY, Cai H, Zhou QF, Kong XM. beta-Elemene alleviates bone cancer-related pain in rats by modulating N-methyl-D-aspartate receptor 2B subunit. Trop J Pharm Res. 2018;17(4):597-603.

\section{Publish your work in this journal}

The Journal of Pain Research is an international, peer reviewed, open access, online journal that welcomes laboratory and clinical findings in the fields of pain research and the prevention and management of pain. Original research, reviews, symposium reports, hypothesis formation and commentaries are all considered for publication. The manuscript management system is completely online and includes a very quick and fair peer-review system, which is all easy to use. Visit http:// www.dovepress.com/testimonials.php to read real quotes from published authors. 